\title{
MiR-142-3p is downregulated in aggressive p53 mutant mouse models of pancreatic ductal adenocarcinoma by hypermethylation of its locus
}

\author{
Jack D. Godfrey $\mathbb{D}^{1}$, Jennifer P. Morton ${ }^{2,3}$, Ania Wilczynska', Owen J. Sansom $\mathbb{B}^{2,3}$ and Martin D. Bushell ${ }^{1}$
}

\begin{abstract}
Pancreatic ductal adenocarcinoma (PDAC) is an extremely aggressive disease with poor prognostic implications. This is partly due to a large proportion of PDACs carrying mutations in TP53, which impart gain-of-function characteristics that promote metastasis. There is evidence that microRNAs (miRNAs) may play a role in both gain-of-function TP53 mutations and metastasis, but this has not been fully explored in PDAC. Here we set out to identify miRNAs which are specifically dysregulated in metastatic PDAC. To achieve this, we utilised established mouse models of PDAC to profile miRNA expression in primary tumours expressing the metastasis-inducing mutant $\mathrm{p} 53^{\mathrm{R} 172 \mathrm{H}}$ and compared these to two control models carrying mutations, which promote tumour progression but do not induce metastasis. We show that a subset of miRNAs are dysregulated in mouse PDAC tumour tissues expressing mutant $\mathrm{p} 53^{\mathrm{R} 172 \mathrm{H}}$, primary cell lines derived from mice with the same mutations and in TP53 null cells with ectopic expression of the orthologous human mutation, $p 53^{\mathrm{R} 175 \mathrm{H}}$. Specifically, miR-142-3p is downregulated in all of these experimental models. We found that DNA methyltransferase 1 (Dnmt1) is upregulated in tumour tissue and cell lines, which express $\mathrm{p} 53^{\mathrm{R} 172 \mathrm{H}}$. Inhibition or depletion of Dnmt1 restores miR-142-3p expression. Overexpression of miR-142-3p attenuates the invasive capacity of $\mathrm{p} 53^{\mathrm{R} 172 \mathrm{H}}$-expressing tumour cells. MiR-142-3p dysregulation is known to be associated with cancer progression, metastasis and the miRNA is downregulated in patients with PDAC. Here we link TP53 gain-of-function mutations to Dnmt1 expression and in turn miR-142-3p expression. Additionally, we show a correlation between expression of these genes and patient survival, suggesting that they may have potential to be therapeutic targets.
\end{abstract}

\section{Introduction}

PDAC is the most common and most aggressive form of pancreatic cancer and has very poor prognosis, with an average 5 -year survival of $<10 \%{ }^{1}$. This is often due to the disease being diagnosed only after metastatic onset, and its resistance to conventional therapeutics ${ }^{2}$. A better understanding of the molecular events governing PDAC

Correspondence: Martin D. Bushell (mb446@le.ac.uk)

${ }^{1}$ Medical Research Council Toxicology Unit, Lancaster Rd, Leicester LE1 7HB, UK ${ }^{2}$ Cancer Research UK Beatson Institute, Garscube Estate, Switchback Road, Glasgow G61 1BD, UK

Full list of author information is available at the end of the article.

Edited by G. Raschell $\tilde{A}$ progression is required to develop more suitable therapeutic interventions.

Around $90 \%$ of sporadic human PDACs are initiated by mutations to the $K$-RAS proto-oncogene, which results in constitutive activation of K-RAS signalling ${ }^{3}$. Mouse studies with targeted mutation of Kras develop pancreatic intraepithelial neoplasia (PanIN), which progress slowly and lead to malignant adenocarcinomas at a low frequency ${ }^{4}$. The majority of mutant Kras-induced PanINs undergo senescence and require further mutations in tumour suppressors, such as $\operatorname{Trp} 53^{5,6}, C d k n 2 a^{7}, \operatorname{Tg} f b r 2^{8}$, Smad4 $4^{9}$ or Pten ${ }^{10,11}$, to progress into invasive adenocarcinomas.

\section{(c) The Author(s) 2018}

(c) (i) Open Access This article is licensed under a Creative Commons Attribution 4.0 International License, which permits use, sharing, adaptation, distribution and reproduction cc) in any medium or format, as long as you give appropriate credit to the original author(s) and the source, provide a link to the Creative Commons license, and indicate if changes were made. The images or other third party material in this article are included in the article's Creative Commons license, unless indicated otherwise in a credit line to the material. If material is not included in the article's Creative Commons license and your intended use is not permitted by statutory regulation or exceeds the permitted use, you will need to obtain permission directly from the copyright holder. To view a copy of this license, visit http://creativecommons.org/licenses/by/4.0/. 
Mutations in TP53 are present in $\sim 40-70 \%$ of PDAC patients ${ }^{12}$. The majority of these mutations occur in the DNA-binding domain of TP53, resulting in a protein which lacks the capacity to bind $\mathrm{DNA}^{13}$. The mutated TP53 proteins have dominant-negative effects on transcription as the insertion of just one mutated version into the TP53 homo-tetramer prevents its function ${ }^{14}$. Additionally, a number of studies have shown that specific mutations in TP53, such as $\mathrm{p} 53^{\mathrm{R} 172 \mathrm{H}}$, impart additional gain-of-function characteristics, including initiation of metastasis, which are not observed following TP53 loss ${ }^{5,6}$.

Mutations to PTEN are not observed with high frequency in human PDACs, though hyper-activation of signalling pathways normally inhibited by PTEN, such as PI3K, is observed in $~ 60 \%$ of cases ${ }^{15}$. However, when they do occur, they allow cells to bypass $K$-RAS-induced senescence in PanIN lesions ${ }^{11}$ and thus promote formation of PDAC. Importantly, mutations to PTEN have not been shown to induce metastasis in PDAC ${ }^{11}$.

The incidence of the gain-of-function TP53 mutations, including $\mathrm{p} 53^{\mathrm{R} 172 \mathrm{H}}$ ( $\mathrm{R} 175 \mathrm{H}$ in humans), in aggressive tumours and their documented functional role in metastasis testifies to their importance, but their full molecular impact has not yet been elucidated ${ }^{6,16-18}$. A number of studies have strongly implicated miRNAs and their key biogenesis enzymes, Drosha and Dicer, as critical mediators of mutant TP53 activity. Mutant TP53 has been shown to interfere with Drosha interactions with DEADbox protein $5(\mathrm{DDX} 5 / \mathrm{p} 68)^{19}$ and DEAD-box protein 17 $(\mathrm{DDX} 17 / \mathrm{p} 72 / \mathrm{p} 82)^{20}$, leading to reduced processing of specific subsets of primary miRNAs. Moreover, previous studies have shown that decreased Dicer expression can result in metastasis ${ }^{21,22}$ and this process may involve members of the TP53 family ${ }^{23,24}$. Mutant TP53 has also been shown to interact with and inhibit other members of the TP53 family: TAp63 and TAp $73^{25}$. In fact, miRNAs which are direct transcriptional targets of TAp63, miR$130 b^{26}$ and $l e t-7 i^{17}$ have been shown to be downregulated by mutant TP53.

Together these studies strongly suggest that miRNAs are key mediators acting downstream of gain-of-function TP53 mutations. MiRNAs relay their activity by negatively regulating gene expression through base pairing with hundreds of target mRNAs thus controlling gene expression networks and giving them the potential to affect complex cellular mechanisms such as metastasis ${ }^{27}$. Because of these observations, we wished to specifically focus on the miRNAs which were regulated in mouse models of PDAC carrying the gain-of-function mutant $\mathrm{p} 53^{\mathrm{R} 172 \mathrm{H}}$. While miRNA expression profiles of PDAC in primary patient samples have previously been published ${ }^{28}$, none have looked specifically at how mutant TP53 affects miRNA expression in this disease. This is critical given that mutant TP53 has been shown to induce metastasis, which is the predominant cause of cancer-related morbidity and mortality. Here we show that mutant $\mathrm{p} 53^{\mathrm{R} 172 \mathrm{H}}$ inhibits expression of $m i R-142-3 p$, a microRNA known to drive invasion and metastasis in PDAC $^{29}$. We show that this occurs through a DNMT1-dependent mechanism leading to increased genomic methylation around the $m i R-142-3 p$ genomic locus. Importantly, we show that both DNMT1 and miR-142-3p expression correlate with patient survival, which may provide opportunities for therapeutic intervention.

\section{Results}

\section{Mutant $\mathrm{p} 53^{\mathrm{R} 172 \mathrm{H}}$ expression leads to downregulation of a subset of miRNAs in PDAC}

The aim of this study was to identify miRNAs, which were dysregulated by the gain-of-function $\mathrm{p} 53^{\mathrm{R} 172 \mathrm{H}}$ mutant in PDAC and thus potentially involved in metastasis as opposed to loss of p53 function, which does not cause metastasis ${ }^{5,6}$. Pdx1-Cre; LSL-Kras ${ }^{G 12 D /+} ;$ LSL$\operatorname{Trp} 53^{R 172 H /+}$ (KPC) mice carry pancreas-specific mutant Kras $^{\mathrm{G} 12 \mathrm{D}}$ and gain-of-function $\mathrm{p} 53^{\mathrm{R} 172 \mathrm{H}}$ and develop invasive and metastatic PDAC ${ }^{5}$. Tumour tissue from these mice (hereafter referred to as Kras $\mathrm{p} 53^{\mathrm{R} 172 \mathrm{H}}$ ) was studied, along with tumour tissue from Pdx1-Cre; LSL-Kras ${ }^{G 12 D /+}$; LSL-Trp53 ${ }^{\text {flox/+ }}\left(\right.$ Kras p53 $\left.{ }^{\text {flox }}\right)$ mice and Pdx1-Cre; LSLKras $^{\text {G12D/+ }}$; Pten ${ }^{\text {flox/+ }}$ (Kras Pten ${ }^{\text {flox }}$ ) mice, both of which develop PDACs that rarely metastasise ${ }^{6,11}$. The use of these two controls allowed us to differentiate between microRNAs whose expression is dependent on WT p53 and those regulated by the $\mathrm{p} 53^{\mathrm{R} 172 \mathrm{H}}$ gain-of-function mutant. This is particularly important as previous studies have suggested that mutant $\mathrm{p} 53^{\mathrm{R} 172 \mathrm{H}}$ gain-of-function is responsible for metastasis ${ }^{5,6}$. As Kras $\mathrm{p} 53^{\text {flox }}$ cells have lower Trp53 expression than Kras Pten ${ }^{\text {flox }}$ cells, microRNAs which show no change in expression between the controls but are significantly different in the Kras $\mathrm{p} 53^{\mathrm{R} 172 \mathrm{H}}$ condition are likely to be changing due to gain of function rather than dominant-negative activity of mutant p5 $3^{\mathrm{R} 172 \mathrm{H}}$. Global miRNA expression profiles were investigated using miRNA microarrays, interrogating total RNA from mouse primary PDAC tissues.

MiRNAs were included in the study if all of the samples within at least one of the conditions had detectable signals for it in the microarray. Using this cutoff, a total of 307 miRNAs were detected (Fig. 1a). Statistical analysis identified 61 miRNAs which were significantly differentially expressed in the Kras $\mathrm{p} 53^{\mathrm{R} 172 \mathrm{H}}$ samples compared to the Kras Pten ${ }^{\text {flox }}$ samples, and six miRNAs which were significantly differentially expressed in the Kras p $53^{\mathrm{R} 172 \mathrm{H}}$ samples compared to the Kras $\mathrm{p} 53^{\text {flox }}$ samples (Supplemental Fig. 1). A total of four miRNAs, miR-142-3p, miR$30 c-2-3 p, m i R-340-5 p$ and $m i R-378 b$, were found to be dysregulated in the Kras $\mathrm{p} 53^{\mathrm{R} 172 \mathrm{H}}$ tissues compared to both the Kras $\mathrm{p} 53^{\text {flox }}$ and Kras Pten ${ }^{\text {flox }}$ tissues. All four 


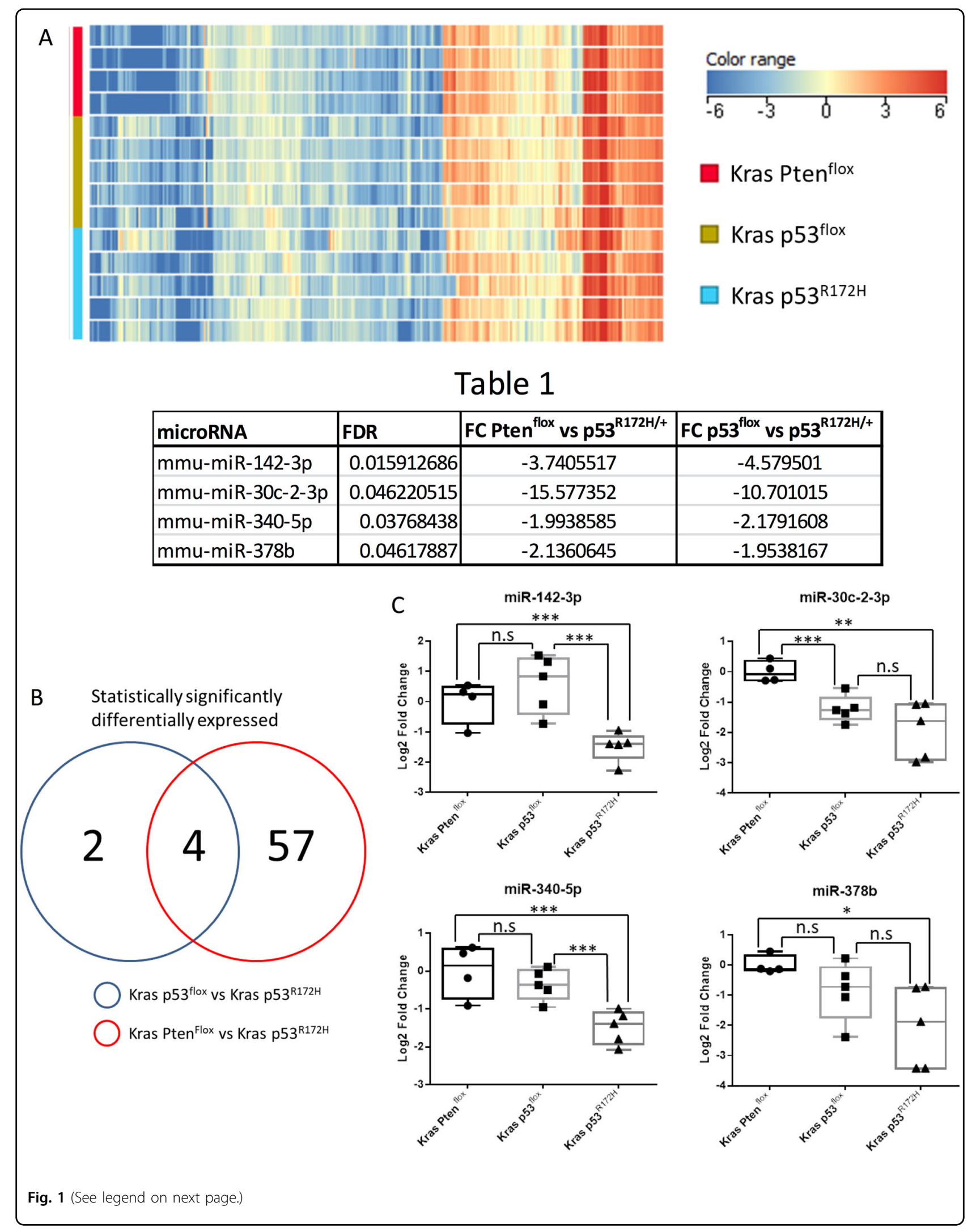


(see figure on previous page)

Fig. 1 Global profiling of microRNA expression in tissues from PDAC mouse models. a Agilent microRNA microarrays were used to investigate global microRNA expression profiles from Kras $\operatorname{Pten}^{\text {flox }}(n=4)$, Kras p53 $3^{\text {flox }}(n=5)$ and Kras p53 ${ }^{\mathrm{R} 172 \mathrm{H}}(n=5)$-expressing mouse pancreatic tumour tissues. Heat map shows the hierarchal clustering and expression levels of microRNAs for all the samples in the analysis. Statistical analysis and fold changes presented in Table 1 were calculated using a one-way ANOVA with post hoc analysis using Tukey's honest significance difference test (HSD) with an FDR (Benjamini Hochberg)-adjusted $p$ value cutoff of 0.05 . A list of all statistically significantly changed microRNAs can be found in

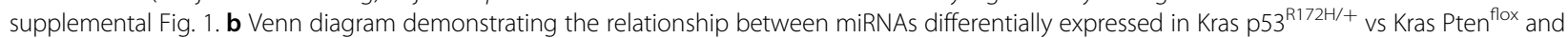

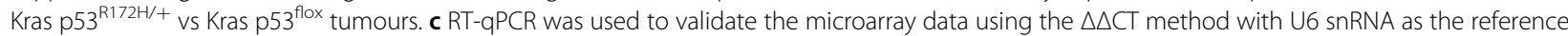
gene. A two-sample, two-tailed, unpaired $t$-test was used to compare the $\triangle C T$ values from each group. Statistical significance is represented as ${ }^{*} p<$ $0.05,{ }^{* *} p<0.01$ and ${ }^{* * *} p<0.005$

were downregulated in the Kras $\mathrm{p} 53^{\mathrm{R} 172 \mathrm{H}}$ tissues (Fig. $1 \mathrm{~b}$ and Table 1). RT-qPCR validation confirmed that the expression of $m i R-142-3 p$ and $m i R-340-5 p$ does not differ between the two control conditions (Kras p53 $3^{\text {flox }}$ and Kras Pten ${ }^{\text {flox}}$ ), but both miRNAs are significantly downregulated in the Kras p53 ${ }^{\mathrm{R} 172 \mathrm{H}}$ tissues (Fig. 1c). Expression of miR-30c-2-3p and miR-378b was found to be significant between Kras Pten ${ }^{\text {flox }}$ and Kras $\mathrm{p} 53^{\mathrm{R} 172 \mathrm{H}}$ but not between Kras Pten ${ }^{\text {flox }}$ and Kras $\mathrm{p} 53^{\mathrm{R} 172 \mathrm{H}}$ (Fig. 1c). This suggests that $m i R-142-3 p$ and $m i R-340-5 p$ expression is directly affected by mutant $\mathrm{p} 53^{\mathrm{R} 172 \mathrm{H}}$ expression.

This analysis provides information about miRNA expression changes in the physiological context of the primary tumour environment in mouse models. However, tissues are inherently heterogeneous with respect to cellular populations. In order to test whether the miRNAs dysregulated in the Kras p5 $3^{\mathrm{R} 172 \mathrm{H}}$ tissues were specifically downregulated in tumour cells, we employed primary cell lines derived from each of the tumour models. As expected, Kras Pten ${ }^{\text {flox }}$ cell lines do not express PTEN, consistent with $\mathrm{LOH}$ during tumour progression as described previously ${ }^{11}$, and similarly Kras $\mathrm{p} 53^{\text {flox }}$ cell lines do not express p53 as the remaining wild-type allele is lost during tumourigenesis (Fig. 2a). Thus, p53 was only observed in Kras p $53^{\mathrm{R} 172 \mathrm{H}}$ lines, where the mutant protein is insensitive to degradation (Fig. 2a). RT-qPCR of the cells lines showed that expression of miR-142-3p follows the profile observed in the tissue samples, with no difference between the control conditions (Kras $\mathrm{p} 53^{\text {flox }}$ and Kras $\mathrm{p} 53^{\mathrm{R} 172 \mathrm{H}}$ ) and a significant downregulation in the mutant Kras p53 ${ }^{\mathrm{R} 172 \mathrm{H}}$ cells (Fig. 2b). The expression of the other miRNAs identified in tissue samples did not show the same pattern of changes which might indicate that the observed differences in tissue may be due to their heterogeneity (Fig. 2b).

Next, we used a murine Kras p53 ${ }^{\text {flox }}$ cell line with ectopic expression of the analogous human mutant TP5 $3^{\mathrm{R} 175 \mathrm{H}}$ to show that the human orthologue of this mutation was also capable of affecting the expression of the miRNAs of interest ${ }^{6}$. As tumours in Kras $\mathrm{p} 53^{\text {flox }}$ mice undergo loss of the remaining wild-type Trp53 allele, wild-type p53 is not expressed in these cells. This allowed us to exclude that the observed changes in miRNA expression are due to the dominant-negative effect of mutant p53 on wild type. Western blot analysis confirmed that TP53 is only present in the cell line with ectopic expression of mutant p53 ${ }^{\mathrm{R} 175 \mathrm{H}}$ (Fig. 2c). Ectopic expression of mutant $\mathrm{p} 53^{\mathrm{R} 175 \mathrm{H}}$ led to a downregulation of $m i R$ $142-3 p$, which confirmed our results for the mouse protein. No change was observed for $m i R-30 c-2-3 p$ and expression of $m i R-340-5 p$ and $m i R-378 b$ were increased (Fig. 2d), again indicating that the altered expression of these miRNAs is not a reproducible hallmark of mutant p53 expression in isolated tumour-derived cells. As there is no wild-type p53 expressed in these cells for the mutant $\mathrm{p} 53^{\mathrm{R} 175 \mathrm{H}}$ to act upon in a dominant-negative manner, this strongly suggests that $m i R-142-3 p$ is being downregulated due to the gain-of-function activity of this mutant. In addition, these data show that the human orthologue of the TP53 mutant is also able to affect the expression of miR-142-3p.

\section{Dnmt1 is dysregulated by mutant $\mathrm{p} 53^{\mathrm{R} 172 \mathrm{H}}$ in PDAC}

Our investigations of the PDAC models did not uncover any global changes in mature miRNA expression, so we focused on regulatory mechanisms pertaining to the specific dysregulation of $m i R-142-3 p$ expression. Since DNA methylation has been found to be both upregulated $^{30-33}$ and downregulated ${ }^{34-36}$; in a number of cancer types including PDAC, we reasoned that dysregulated methylation may be responsible for the observed changes in $m i R-142-3 p$ expression. Dnmt1 mRNA expression was investigated in the primary tumour tissue from the PDAC models and was found to be elevated in tumours from the Kras $\mathrm{p} 53^{\mathrm{R} 172 \mathrm{H}}$ tissues compared to both Kras $\mathrm{p} 53^{\text {flox }}$ and Kras Pten ${ }^{\text {flox }}$ tissues (Fig. 3a). Dmnt1 mRNA (Fig. 3b) and protein (Fig. 3c) were also found to be upregulated in the Kras $\mathrm{p} 53^{\mathrm{R} 172 \mathrm{H}}$ cell line compared to both the Kras p53 flox and Kras Pten ${ }^{\text {flox }}$ cell lines.

\section{MiR-142-3p expression can be rescued by inhibition of methylation}

As we observed an inverse correlation between $m i R$ $142-3 p$ and Dnmt1 expression, we asked if inhibiting 


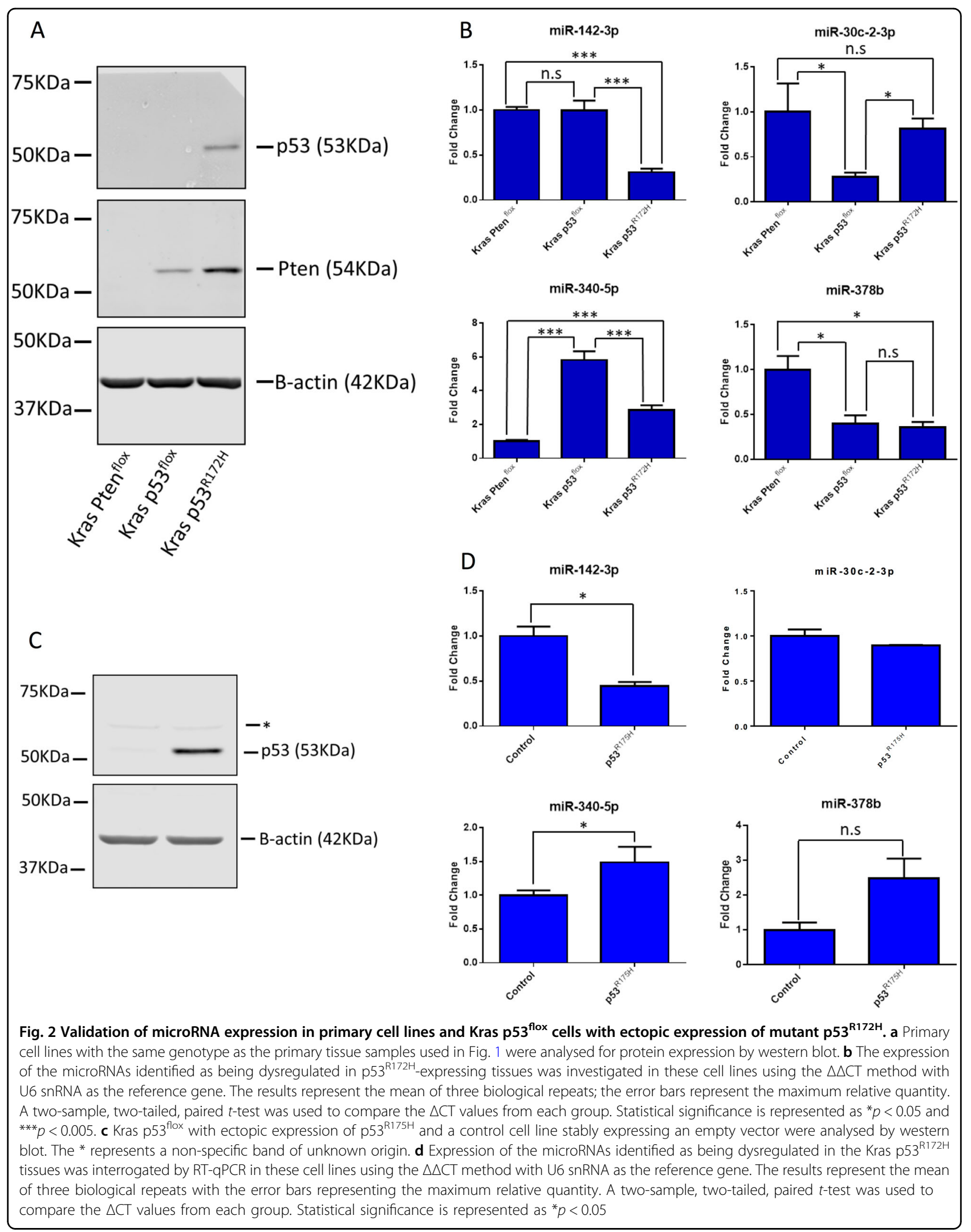



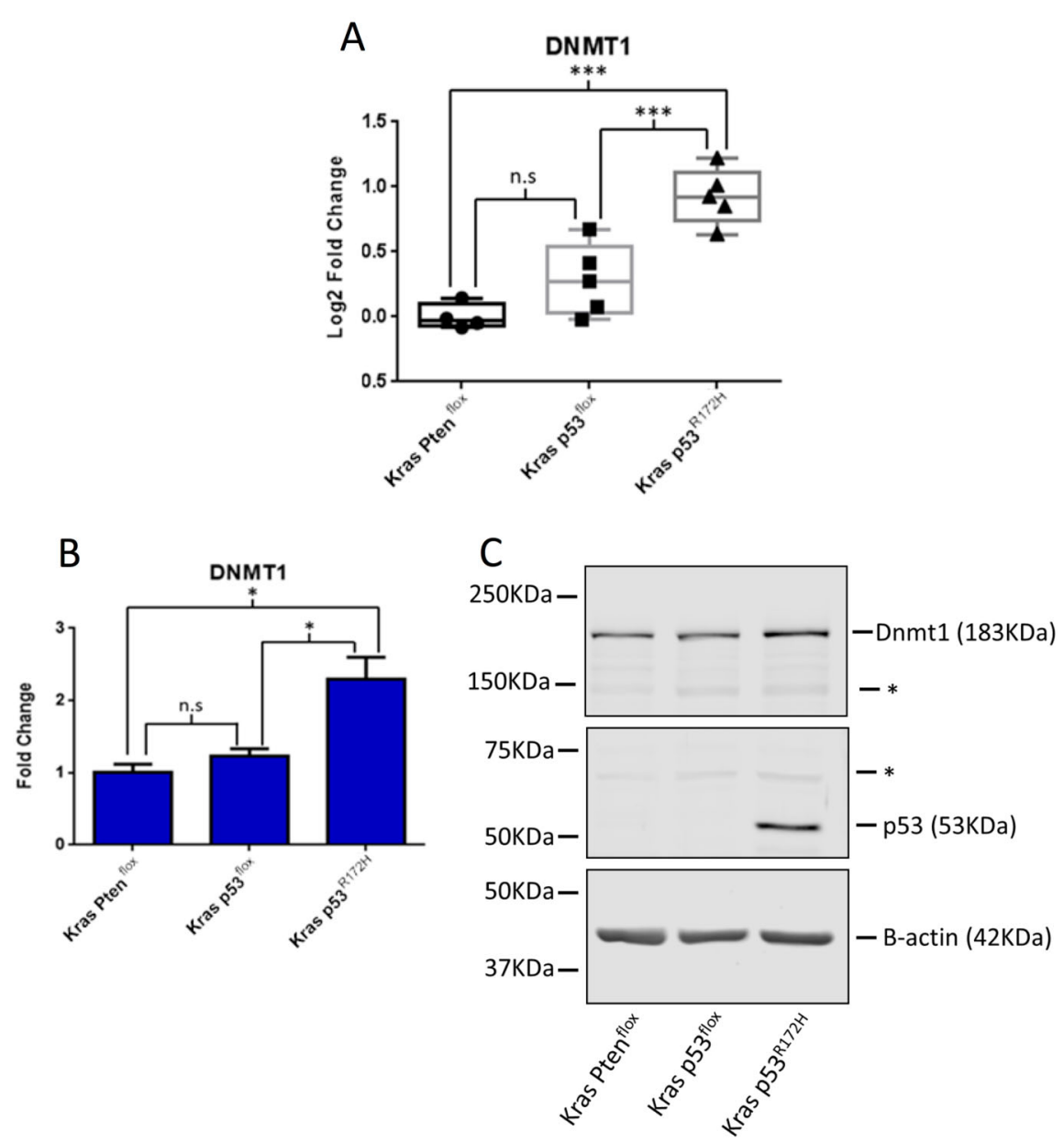

Fig. 3 Protein and mRNA expression of Dnmt1 in PDAC mouse models. a RT-qPCR of Dnmt1 mRNA abundance in primary mouse tissues. The $\triangle \triangle C T$ method was used to calculate fold change using $\beta$-actin as the reference gene with the fold change being relative to the Kras Pten ${ }^{\text {flox }}$ samples. The * represent non-specific bands of unknown origin. $\mathbf{b}$ RT-qPCR of Dnmt1 expression in primary cell lines. The $\triangle \Delta C T$ method was used to calculate fold change with $\beta$-actin as the reference gene with fold change normalised to the Kras Pten ${ }^{\text {flox }}$ cell line. The result represents the mean of three biological repeats with the error bars representing the maximum relative quantity. A two-sample, two-tailed, paired $t$-test was used to compare the $\Delta C T$ values from each group. Statistical significance is represented as ${ }^{*} p<0.05$ and ${ }^{* *} p<0.005$. c A representative western blot showing the expression of Dnmt1, Pten, $p 53$ and $\beta$-actin in the primary cell lines

DNA methylation had an impact on miR-142-3p expression levels. We utilised 5-aza-2-deoxycytidine (5-aza-DC), which inhibits DNMT1, DNMT3A and DNMT3B by being incorporated into nascent DNA, where it cross links with $D N M T$ protein family members, sequestering them and reducing global methylation ${ }^{37}$. Treatment of the Kras $\mathrm{p} 53^{\mathrm{R} 172 \mathrm{H}}$ cell line for $24 \mathrm{~h}$ with $1 \mu \mathrm{M}$ of 5 -aza-DC led to a significant induction of miR-142-3p while having no effect on the expression of other miRNAs investigated in this study (Fig. 4). As 5-aza-DC is a functional inhibitor of all members of the DNMT family ${ }^{38}$, we asked if specific inhibition of Dnmt1 was also able to affect miR-142-3p expression. As in the case of 5-aza-DC treatment, expression of $m i R-142-3 p$ was significantly increased following depletion of Dnmt1 in the Kras $\mathrm{p} 53^{\mathrm{R} 172 \mathrm{H}}$ cell line
(Fig. 5a, b). The other miRNAs under investigation showed mild to no change in expression following Dnmt1 depletion, demonstrating selectivity for miR-142-3p.

The miR-142 genomic locus is hypermethylated in mutant p5 $3^{\mathrm{R} 172 \mathrm{H}}$-expressing primary cell lines

As direct depletion of Dnmt1 and a methylationinhibiting drug were both shown to induce miR-142-3p expression, direct analysis of CpG dinucleotides in the miR-142 genomic locus was carried out. A CpG island which overlaps the miR-142 genomic locus was identified using Methyl Primer Express software (Applied Biosystems, Waltham, MA, USA) (Fig. 6). Bisulphite sequencing of a $378 \mathrm{bp}$ fragment of the CPG island was carried out using DNA from both the Kras p $53^{\text {flox }}$ and Kras p $53^{\text {R172H }}$ 
miR-142-3p

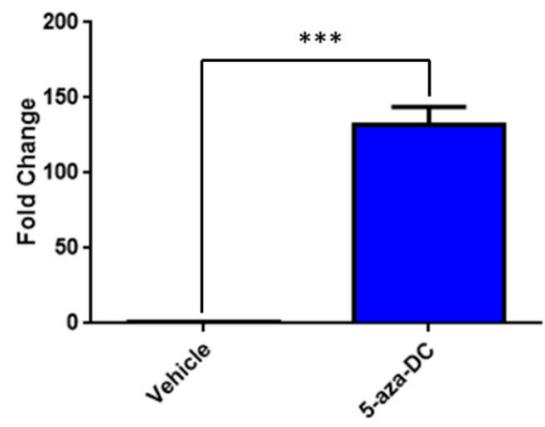

miR-340-5p

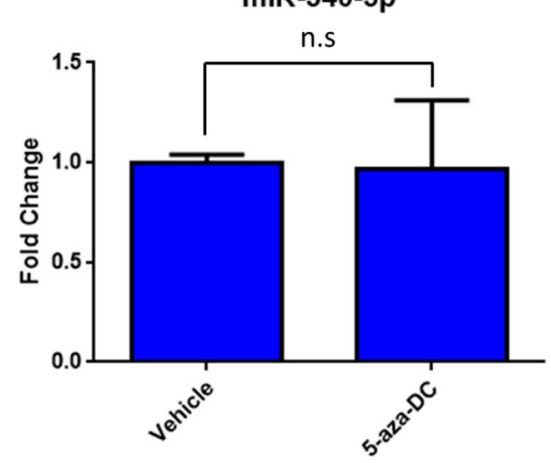

miR-30c-2-3p

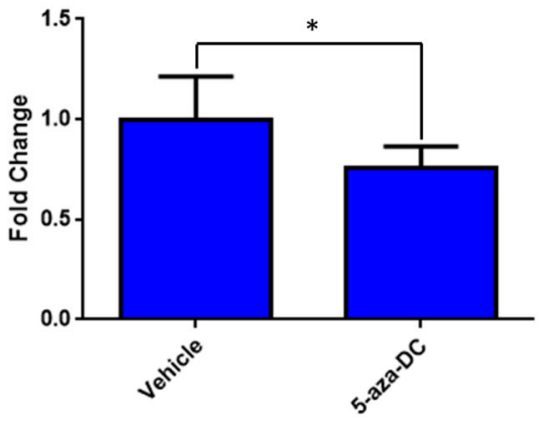

miR-378b

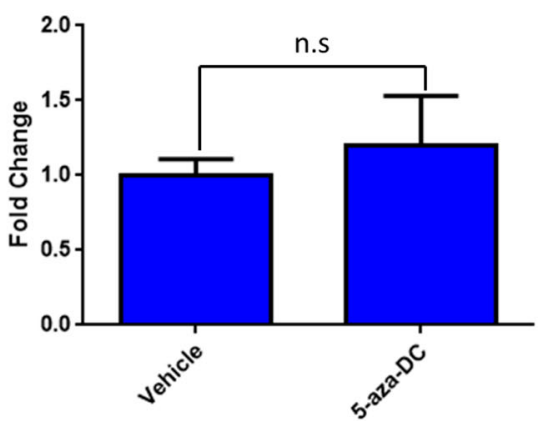

Fig. 4 Expression of microRNAs following treatment with 5 -aza-deoxycytidine. The Kras p53 $3^{\mathrm{R} 172 \mathrm{H} /+}$ cell line was treated with $1 \mu \mathrm{m}$-azadeoxycytidine (5-aza-Dc) or an equal volume of a vehicle control (DMSO) for $24 \mathrm{~h}$. The expression of the microRNAs identified as dysregulated in p53 $3^{\mathrm{R} 172 \mathrm{H}}$-expressing tissues was quantified by RT-qPCR with U6 snRNA as the reference gene. The result represents the average of three biological repeats with the error bars representing the maximum relative quantity. A two-sample, two-tailed, paired t-test was used to compare the $\Delta C T$ values from each group. Statistical significance is represented as ${ }^{*} p<0.05$ and ${ }^{* * *} p<0.005$

cell lines and clearly showed high levels of methylation of this region in both cell lines. Importantly, a statistically significant increase in methylation was observed in the fragment from the Kras $\mathrm{p} 53^{\mathrm{R} 172 \mathrm{H}}$ cell line (Fig. 6).

\section{Overexpression of miR-142-3p inhibits $\mathrm{p} 53^{\mathrm{R} 172 \mathrm{H}}$-driven invasion in vitro}

Given that mutant $\mathrm{p} 53^{\mathrm{R} 172 \mathrm{H}}$ has been shown to drive invasion and metastasis in $\mathrm{PDAC}^{6}$, we investigated the impact of overexpression of miR-142-3p on cell invasion. Using reverse transwell invasion assays ${ }^{6}$, we confirmed that Kras p $53^{\text {flox }}$ cells have almost no invasive ability while Kras p53 ${ }^{\mathrm{R} 172 \mathrm{H}}$ cells are invasive (Fig. 7a, b). This is in line with previously published data ${ }^{6}$. Importantly, overexpression of miR-142-3p in the Kras p53 ${ }^{\mathrm{R} 172 \mathrm{H}}$ cells leads to a significant reduction in the invasive potential of these cells in vitro (Fig. $7 \mathrm{a}-\mathrm{c}$ ).

\section{Low miR-142-3p expression and high DNMT1 expression correlate with poor survival in human cancers}

The data we present here identify a novel mechanism by which mutant $\mathrm{p} 53^{\mathrm{R} 172 \mathrm{H}}$ is able to decrease expression of $m i R-142-3 p$ in a mouse model of PDAC, through genomic hypermethylation due to increased expression of DNMT1. Therefore, we wished to determine whether $m i R-142-3 p$ or DNMT1 expression correlates with human patient survival.

Bioinformatic analysis using the YM500v3 database allowed us to examine 8000 small RNA sequencing data sets and correlate survival statistics associated with their expression $^{39}$. This revealed a strong correlation between poor survival and low $m i R-142-3 p$ expression in human PDAC (Fig. 8a). The ProGENEV2 database ${ }^{40}$ was used to investigate any correlation between DNMT1 expression and patient survival in PDAC. This revealed that high DNMT1 mRNA expression correlates with poor survival in human PDAC patients (Fig. 8b).

\section{Discussion}

Three mouse models of PDAC were used in this study: two in which metastasis occurs only at low-frequency Kras $\mathrm{p} 53^{\text {flox }}$ and Kras Pten ${ }^{\text {flox }}$, and Kras $\mathrm{p} 53^{\mathrm{R} 172 \mathrm{H}}$, in which metastasis occurs at high frequency. Murine primary pancreatic tumour tissues and primary cell lines, as well as ectopic expression of human mutant $\mathrm{p} 53^{\mathrm{R} 175 \mathrm{H}}$ in TP53 null cells, all showed that $m i R-142-3 p$ is 

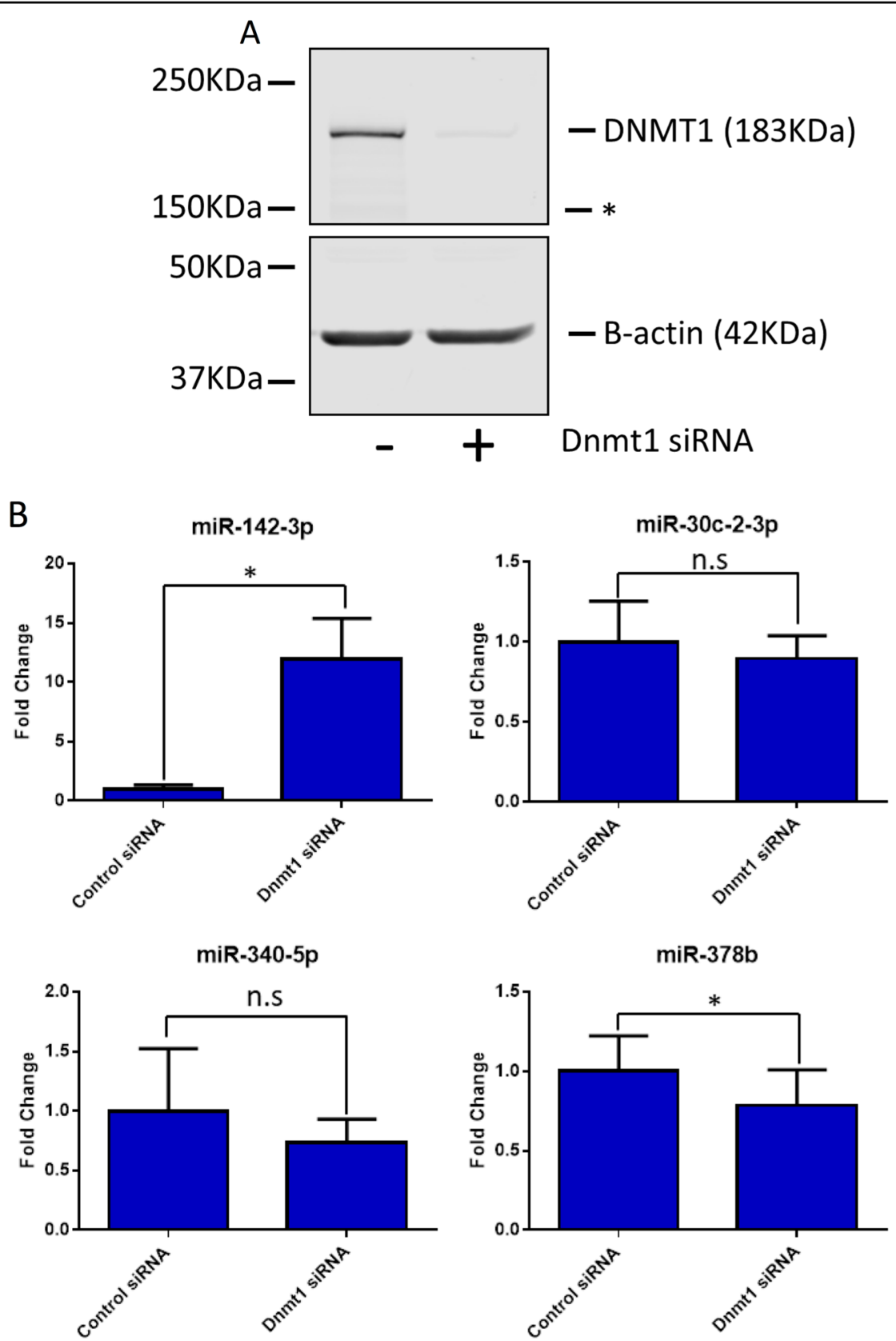

Fig. 5 Expression of microRNAs following depletion of Dnmt1. The Kras $p 53^{\mathrm{R} 172 \mathrm{H}}$ cell line was treated with $20 \mathrm{nM}$ DNMT1 siRNA or a control siRNA for $48 \mathrm{~h}$. a A representative western blot showing the expression of Dnmt1 and p53 following Dnmt1 depletion with $\beta$-actin as a loading control. The * represents a non-specific band of unknown origin. $\mathbf{b}$ The expression of the microRNAs dysregulated in p53 ${ }^{\mathrm{R} 172 \mathrm{H}}$-expressing tissues was quantified after Dnmt1 depletion by RT-qPCR with U6 snRNA as the reference gene. The result represents the mean of three biological repeats with error bars representing the maximum relative quantity. A two-sample, two-tailed, paired $t$-test was used to compare the $\Delta C T$ values from each group. Statistical significance is represented as ${ }^{*} p<0.05$

downregulated in mutant $\mathrm{p} 53^{\mathrm{R} 172 \mathrm{H}}$ or $\mathrm{p} 53^{\mathrm{R} 175 \mathrm{H}}$-expressing PDAC.

A recent study found that $m i R-142-3 p$ is downregulated in human PDAC when compared to paired adjacent normal tissue and in pancreatic cancer cell lines, and showed that hypoxia-inducible factor $(H I F 1 \alpha)$ is a direct target of $m i R-142-3 p$ in PDAC ${ }^{29}$. High HIF1 $\alpha$ expression leads to increased proliferation and invasion of tumour cells as well as inducing expression of genes involved in EMT, such as vimentin, VEGF and E-cadherin. Meanwhile, low expression of miR-142-3p correlated with an increased incidence in lymphatic metastasis. These results 


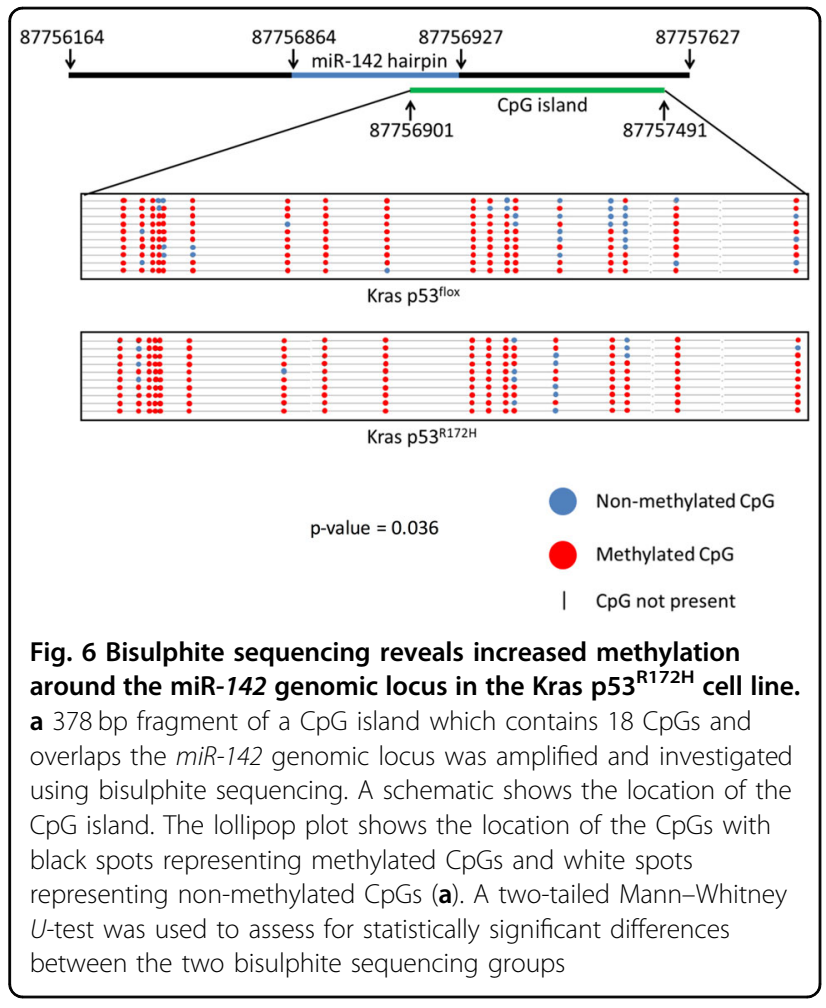

taken together with our findings identify both direct and downstream secondary targets by which miR-142-3p functions in human patients and link its expression to invasion and metastasis. Additionally, two recent studies have shown that increasing miR-142-3p expression in acute myelogenous leukaemia ${ }^{41}$ and non-small cell lung cancer ${ }^{42}$ improves chemosensitivity by decreasing autophagy due to translational repression of $H M G B 1$. However, the previously published data does not connect dysregulation of $m i R-142-3 p$ to gain-of-function mutations in TP53 nor does it identify a mechanism by which miR-142$3 p$ is dysregulated. Our data clearly show that the expression of this miRNA is indirectly inhibited by mutant $\mathrm{p} 53^{\mathrm{R} 172 \mathrm{H}}$ via genomic methylation due to increased expression of DNMT1.

Our study also found that mutant $\mathrm{p} 53^{\mathrm{R} 172 \mathrm{H}}$ elevates the expression of Dnmt1 in PDAC. This is in line with previous data, which has found DNMT1 to be upregulated in both PanIN lesions and PDACs ${ }^{43,44}$. Our data show that Dnmt1 mRNA is upregulated in mutant $\mathrm{p} 53^{\mathrm{R} 172 \mathrm{H}}$ expressing tissues and cell lines, suggesting an increase in transcription rate or stabilisation of the Dnmt1 transcript. DNMT1 has been shown to be a transcriptional target of specificity protein $1 \& 3\left(\begin{array}{lll}S P 1 & \& & 45\end{array}\right)^{45}$. A complex formed between $S P 1$ and wild-type TP53 has been shown to bind the promoter of DNMT1 and repress its transcription ${ }^{46}$. Mutant p53 is able to inhibit this complex resulting in upregulation of DNMT1 in lung cancer patients ${ }^{46}$. It is possible that the same mechanism is inducing Dnmt1 transcription in this PDAC model, leading to subsequent hypermethylation of $m i R-142-3 p$.

Previous findings of the impact of $m i R-142-3 p$ on tumour progression along with the data presented in this study, linking mutant $\mathrm{p} 53^{\mathrm{R} 172 \mathrm{H}}$ and DNMT1 expression, suggest that DNMT1 may be a potential therapeutic target in PDAC. However, demethylating drugs have been shown to have limited clinical efficacy. 5-azadeoxycytidine has previously been considered in cancer treatment but was shown to be highly toxic ${ }^{47}$, though more recent studies using low dosage of 5-azadeoxycytidine have demonstrated some clinical efficacy in haematological malignancies and myelodysplastic syndrome ${ }^{48-52}$. A previous study showed that treatment with 5-aza-deoxycytidine in PDAC leads to upregulation of tumour suppressors, but also increased expression of oncogenes which promote metastasis ${ }^{53}$, limiting its use as a therapeutic agent. Interestingly, specifically ablating DNMT1 promotes expression of tumour suppressor genes but does not have the undesirable effect of promoting expression of oncogenes ${ }^{54}$. A number of drugs which directly target DNMT1 are currently in development, though most show limited therapeutic value ${ }^{55}$. One interesting drug is minnelide, a pro-drug of triptolide. Triptolide has been shown to be efficacious in treatment of PDAC through induction of $m i R-142-3 p^{56}$. Another study has shown that triptolide is able to negatively regulate DNMT1 transcription, leading to increased expression of methylated genes ${ }^{57}$. These findings are very much in line with our data which show that Dnmt1 inhibition increases $m i R-142-3 p$ expression and that increasing $m i R$ $142-3 p$ expression reduces the invasive potential of tumour cells. This may suggest that triptolide may be specifically useful in treatment of mutant TP53-expressing PDACs.

The data presented in this study identifies a potential new mechanism by which mutant $\mathrm{p} 53^{\mathrm{R} 172 \mathrm{H}}$ is able to affect gene expression in a gain-of-function manner, through increased expression of DNMT1 which in turn leads to hypermethylation of miR-142-3p and perhaps other genes. These results open up the possibilities for therapeutic targeting of methylation in mutant $\mathrm{p} 53^{\mathrm{R} 172 \mathrm{H}}$ expressing PDACs and other tumour types.

\section{Methods}

\section{Mouse models}

All mouse models have been previously described $^{5,6,11,58}$. Experiments were performed under Home Office licence and approved by the University of Glasgow ethics committee. Mice on a mixed background were maintained in conventional cages with environmental enrichment on a light-dark cycle and given access to standard diet and water ad libitum. Genotyping was performed by Transnetyx (Cordoba, TN, USA). Mice were 


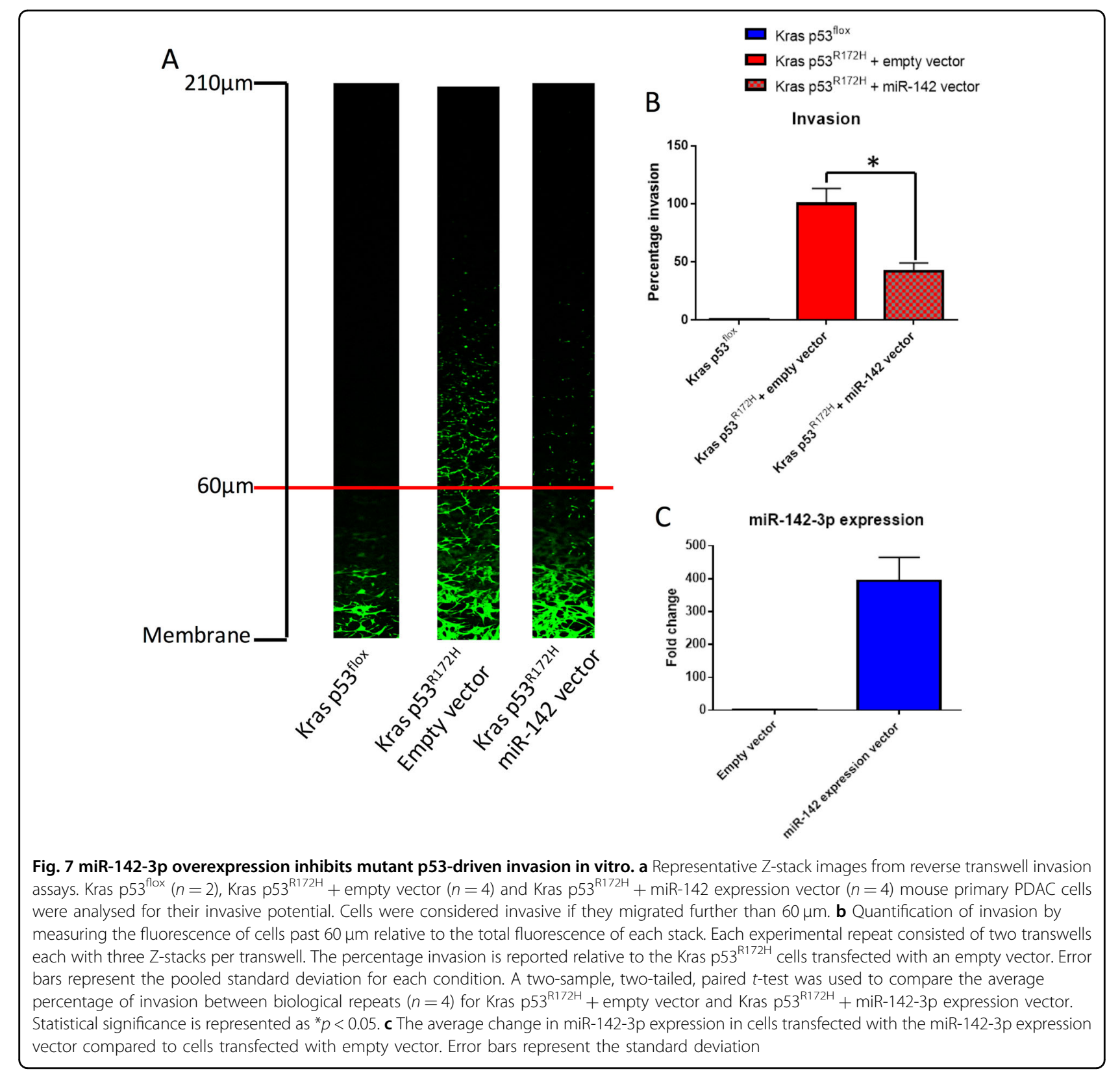

monitored at least three times weekly and culled when exhibiting symptoms of PDAC (swollen abdomen, loss of body conditioning reminiscent of cachexia, jaundice, hunching and immobility). PDAC tissue was collected and stored at $-80^{\circ} \mathrm{C}$ in RNAlater (Ambion, Foster City, CA, USA) until RNA extraction. PDAC cell lines from these models were isolated and grown in house as described previously ${ }^{6,58}$.

\section{RNA extraction}

Tissues were thawed on ice in the presence of RNAlater. Once thawed, tissues were snap frozen in liquid $\mathrm{N}_{2}$ and pulverised in a pestle and mortar before $1 \mathrm{ml}$ of TRIzol
(Thermo Fisher Scientific, Waltham, MA, USA) reagent per $1 \mathrm{mg}$ of tissue was added. Chloroform $(200 \mu \mathrm{l}$ per $1 \mathrm{ml}$ of TRIzol) was then added and the sample was centrifuged at $12,000 \times g$ for $15 \mathrm{~min}$ and the aqueous layer was removed. Isopropanol $(750 \mu \mathrm{l}$ per $1 \mathrm{ml}$ of TRIzol) was then added and the sample was precipitated overnight at $-20^{\circ} \mathrm{C}$. RNA was resuspended in $\mathrm{ddH}_{2} \mathrm{O}$ and an equal volume of acid phenol/chloroform (50:50) was added. The sample was centrifuged at $12,000 \times g$ and the aqueous layer was removed before sodium acetate $(10 \%$ of final volume) and ethanol (250\% of final volume) was added and the sample was precipitated at -20 overnight. Samples were resuspended in a suitable volume of $\mathrm{ddH}_{2} \mathrm{O}$ and 


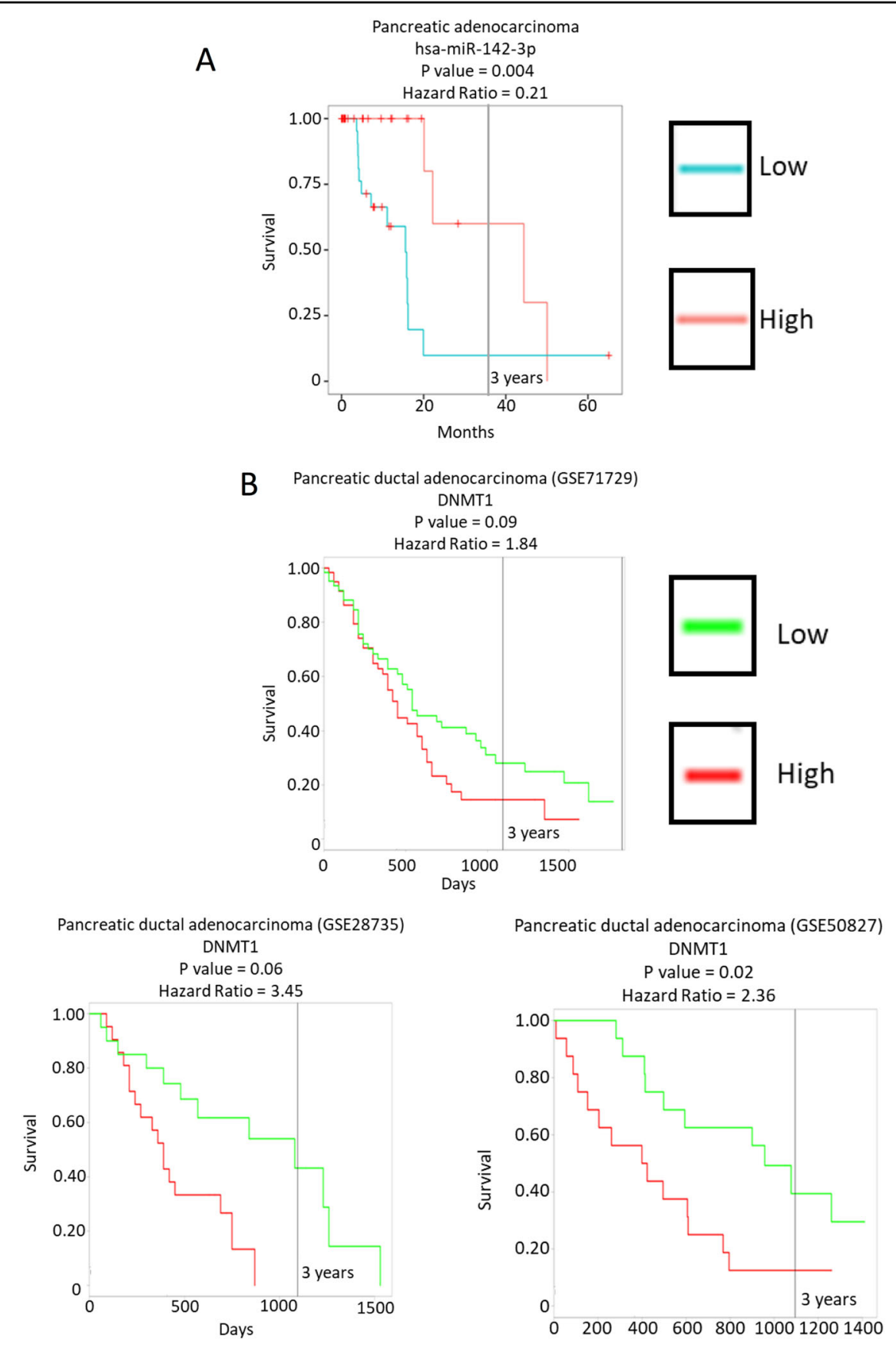

Fig. 8 Low miR-142-3p and high DNMT1 correlate with a poor prognosis in human PDAC. a The data set in the YM500v3 database shows a clear correlation between low miR-142-3p expression and poor survival in human PDAC. b The ProGENEV2 database was interrogated for correlations between DNMT1 expression and human PDAC patient survival. All data sets which show a statistically significant correlation are reported, all of which show a correlation between high DNMT1 expression and poor patient survival

were quantified using a nanodrop spectrophotometer (Thermo Fisher Scientific).

\section{MiRNA microarrays}

Agilent miRNA microarrays were carried out as per the manufacturer's instruction using the Agilent miRNA microarray labelling kit (Agilent, Santa Clara, CA, USA). In brief, $100 \mathrm{ng}$ of total RNA from each PDAC tumour tissues was dephosphorylated and labelled with Cy3-pCp using T4 RNA ligase. The labelled RNA for each sample was then applied to one of the eight miRNA microarrays on each slide and sealed with a gasket cover, before being 
placed in a hybridisation oven at $55^{\circ} \mathrm{C}$ for $20 \mathrm{~h}$ while rotating at $20 \mathrm{rpm}$. The labelled microarrays were scanned using the Agilent G2565CA microarray scanner and the features were defined and extracted using Agilent feature extraction software (version 11.0) using default settings. All fold change and statistical analysis was carried out using Genespring (Agilent). All non-mouse miRNAs were removed from the analysis along with any miRNA, which was not detected in all samples from at least one condition. Statistical analysis was carried out using a one-way ANOVA with a false discover rate (FDR) $p$ value of 0.05 and post hoc analysis using Tukey's honest significant difference test (HSD).

\section{Taqman RT-qPCR}

RT-qPCR of miRNAs was carried out using Taqman miRNA assays (Applied Biosystems) as per the manufacturer's instruction. In brief, 100 ng of total RNA was reverse transcribed using the TaqMan miRNA reverse transcription kit (Applied Biosystems). RT-qPCR was achieved using the Applied Biosystems 7500 RT-qPCR thermocycler under default conditions. The following Taqman assays were used in this study: U6 - 001973, miR-142-3p - 000464, miR-30c-2-3p - 002110, miR-340$5 p-002258$ and $m i R-378 b-465314$ mat.

\section{SYBR green RT-qPCR}

Reverse transcription for RT-qPCR of mRNAs was achieved using Superscript 3 (Invitrogen) reverse transcriptase and random primers as per the manufacturer's instruction. Aliquot of $100 \mathrm{ng}$ of total RNA was used for each reaction. The following primers were used in this study: Dnmt1 forward - GTGCTCTCACCCAGAGCCCC, Dnmt1 reverse - GGGTGCTTGACAGAAGCGCT, $\beta$ actin forward - GTGGACAGTGAGGCCAGGAT, $\beta$ actin reverse - GATTACTGCTCTGGCTCCTAGCA.

\section{Bisulphite sequencing}

DNA was extracted from Kras $\mathrm{p} 53^{\text {flox }}$ and Kras p $53^{\mathrm{R} 172 \mathrm{H}}$ cell lines using the DNeasy blood and tissue kit (Qiagen, Venlo, the Netherlands) as per the manufacturer's instruction. DNA was treated with sodium bisulphite using the EpiTect plus DNA bisulphite kit (Qiagen) as per the manufacture's instruction. Following bisulphite conversion, DNA was washed and eluted from a MinElute DNA spin column. Methyl primer Express software (Applied Biosystems) was used to interrogate a sequence of DNA 700 bp both up and downstream of the miR-142 precursor sequence. Using the definition of a $\mathrm{CpG}$ island as a sequence with a $\mathrm{CpG}$ observed/expected ratio $>0.6$, a 590 bp CpG island was observed overlapping the miR142-3p precursor sequence. Primers were designed to amplify a $378 \mathrm{bp}$ fragment of the CpG island which contained $18 \mathrm{CpG}$ dinucleotides.
PCR was carried out using EpiMark Hot Start Taq DNA Polymerase (NEB) using the following primers: forward TGGATGAGTGTATTGTGGGT and reverse - AACC CCAATAACAAAATCAAAC as per the manufacturer's instruction. The resulting fragment was size excluded on an agarose gel and extracted, before being ligated into pGEM-T Easy (Promega, Madison, WI, USA). The resulting ligation was transformed into $\mathrm{DH} 5 \alpha$ competent cells and selected using blue white screening. A total of ten white colonies were selected and amplified for each Kras p53 ${ }^{\text {flox }}$ and Kras p $53^{\mathrm{R} 172 \mathrm{H}}$ cell line. DNA from the amplified colonies was prepared using Wizard Plus SV Miniprep kit (Promega) and Sanger sequenced using T7 and SP6 primers. A consensus sequence was then created using SeqTrace ${ }^{59}$. Consensus sequences were edited to remove and sequence corresponding to the pGEM-T Easy backbone using BioEdit ${ }^{60}$. The sequences were then compared to the genomic sequence of the $\mathrm{CpG}$ island using BiQ Analyzer ${ }^{61}$. Samples were accepted as individual if they had at least one non-CpG cytosine residue independent of the other samples. Samples were only accepted if they had a conversion efficiency of $>95 \%$ judged by abundance of non-CpG cytosine residues.

\section{SDS-PAGE and western blotting}

Cells were lysed in radioimmunoprecipitation assay buffer (RIPA) (50 mM Tris, $150 \mathrm{mM} \mathrm{NaCl}, 0.1 \%$ SDS, $0.5 \%$ sodium deoxycholate, $1 \%$ NP-40) supplemented with Complete Protease Inhibitor Cocktail Tablets (Roche, Basel, Switzerland) immediately prior to use. The antibodies used in this study were: $\beta$-actin (Sigma, 20-33), PTEN (Cell Signalling, 9552), p53 (Abcam, ab240) and DNMT1 (Cell Signalling, D63A6). Images were revealed using the LI-COR infra-red imager using LI-COR infra-red secondary antibodies.

\section{Cell culture}

All cell lines were grown in DMEM (Gibco, Waltham, MA, USA) supplemented with 10\% Foetal bovine serum (FBS), L-glutamine $(20 \mathrm{mM})$ and penicillin/streptomycin $(50 \mathrm{ug} / \mathrm{ml})$. The TP53 null cell lines with stable ectopic expression of mutant $\mathrm{p} 53^{\mathrm{R} 175 \mathrm{H}}$ were additionally supplemented with G418 $(400 \mu \mathrm{g} / \mathrm{ml})$. All cell lines were grown in a humidified cell culture incubator with $20 \% \mathrm{O}_{2}$ and $5 \%$ $\mathrm{CO}_{2}$ at $37^{\circ} \mathrm{C}$.

\section{siRNA transfection}

All siRNA transfections were achieved using Dharmafect 1 transfection reagent as directed by the manufacturer's instruction. Both DNMT1 (4390771) and control (4390844) siRNAs were purchased from the Silencer Select range of validated siRNAs (Thermo Fisher Scientific). A final concentration of $20 \mathrm{nM}$ siRNA was used for all siRNA transfections. Both RNA and protein lysate were collected $48 \mathrm{~h}$ post transfection. 


\section{5-aza-Deoxycitidine treatment}

Cells were treated with $1 \mathrm{nM} 5$-aza-deoxycitidine or an equivalent volume of vehicle (DMSO) for $48 \mathrm{~h}$ before being collected for analysis.

\section{Reverse Invasion assays}

$60 \mu \mathrm{l}$ of Matrigel was placed into cell culture transwell inserts and incubated at $37^{\circ} \mathrm{C}$ with $5 \% \mathrm{CO}_{2}$ for $1 \mathrm{~h}$ in 12 well plates. The inserts were inverted and $100 \mu \mathrm{l}$ of a 350,000 cells $/ \mathrm{ml}$ suspension was applied to the membrane. Plates were incubated at $37^{\circ} \mathrm{C}$ with $5 \% \mathrm{CO}_{2}$, inverted, for $5 \mathrm{~h}$ to allow adherence. The plates were then reverted and the inserts were washed twice in serum free DMEM, before being placed into fresh wells containing 1 $\mathrm{ml}$ of serum free media. $100 \mu \mathrm{l}$ of media with $10 \%$ serum and $10 \mathrm{ng} / \mathrm{ml}$ Hepatocyte Growth Factor (HGF) was then placed into the transwell and the cells were incubated at $37^{\circ} \mathrm{C}$ and $5 \% \mathrm{CO}_{2}$ for $48 \mathrm{~h}$. Cells were stained in $4 \mathrm{nM}$ Calciene for $1 \mathrm{~h}$ before being imaged using a confocal microscope.

Non-invasive cells were removed from the base of the membrane, before the transwell was placed onto a large coverslip on the stage of a confocal microscope. Z-stacks were taken from the inner surface of the membrane at intervals of $15 \mu \mathrm{m}$ with a total of 15 images being taken. The same positions were used for each transwell in order to reduce user bias. Each experimental repeat consisted of 2 transwells per condition with $3 \mathrm{Z}$-stacks being taken per transwell.

Fluorescence for each image of a stack was quantified using ImageJ. A fluorescent signal of cells past $60 \mu \mathrm{m}$ was considered invasive. The percentage of fluorescent signal past $60 \mu \mathrm{m}$ was calculated as a percentage of the total fluorescent signal for each stack, and an average percentage of invasion was calculated for each transwell. Statistical analysis was carried out using a two-sample, twotailed, paired $t$-test, comparing the average invasion of each transwell in a condition $(n=4)$. Conditions with overexpression of miR-142-3p included a preceding day, where cells were transfected with either an empty vector or one containing the miR-142 primary microRNA sequence. Transfected cells not used for the invasion assay were used to quantify the degree of miR-142-3p overexpression using Taqman assays.

\section{Analysis of human patient survival}

The YM500v3 database was interrogated to see how miR-142-3p expression correlated with human patient survival. A single PDAC data set was used for the analysis. The ProGENEV2 database was used to investigate the effect of DNMT1 expression on human patient survival. Of the six PDAC data sets available, three (GSE28735, GSE50827 and GSE71729) had a $p$ value of $<0.1$ and all correlations found that high DNMT1 mRNA expression correlates with poor survival.

\section{Acknowledgements}

J.D.G., A.W. and M.D.B. were funded by the Medical Research Council, UK. J.P.M. and O.J.S. were core funded by Cancer Research UK (A12481, A11650 and A17196).

\section{Author details}

${ }^{1}$ Medical Research Council Toxicology Unit, Lancaster Rd, Leicester LE1 7HB, UK. ${ }^{2}$ Cancer Research UK Beatson Institute, Garscube Estate, Switchback Road, Glasgow G61 1BD, UK. ${ }^{3}$ Institute of Cancer Sciences, University of Glasgow, Garscube Estate, Switchback Road Glasgow, Glasgow G61 1QH, UK

Conflict of interest

The authors declare that they have no conflict of interest.

\section{Publisher's note}

Springer Nature remains neutral with regard to jurisdictional claims in published maps and institutional affiliations.

Supplementary Information accompanies this paper at (https://doi.org/ 10.1038/s41419-018-0628-4)

Received: 2 February 2018 Revised: 15 April 2018 Accepted: 17 April 2018 Published online: 29 May 2018

References

1. Siegel, R. L., Miler, K. D. \& Jemal, A. Cancer statistics, 2017. CA Cancer J. Clin. 67 7-30 (2017).

2. Chari, S. T. Detecting early pancreatic cancer - problems and prospects. Semin. Oncol. 34, 284-294 (2007).

3. Morris, J. P., Wang, S. C. \& Hebrok, M. KRAS, hedgehog, Wnt and the twisted developmental biology of pancreatic ductal adenocarcinoma. Nat. Rev. Cancer 10, 683-695 (2010)

4. Hingorani, S. R. et al. Preinvasive and invasive ductal pancreatic cancer and its early detection in the mouse. Cancer Cell 4, 437-450 (2003).

5. Hingorani, S. R. et al. Trp53R172H and KrasG12D cooperate to promote chromosomal instability and widely metastatic pancreatic ductal adenocarcinoma in mice. Cancer Cell 7, 469-483 (2005).

6. Morton, J. P. et al. Mutant TP53 drives metastasis and overcomes growth arrest/senescence in pancreatic cancer. Proc. Natl Acad. Sci. USA 107, 246-251 (2010).

7. Aguirrea, A. J. et al. Activated KRAS and INK4a/ARF deficiency cooperate to produce metastatic pancreatic ductal adenocarcinoma. Genes Dev. 17 3112-3126 (2003)

8. ljichi, H. et al. Aggressive pancreatic ductal adenocarcinoma in mice caused by pancreas-specific blockade of transforming growth factor-beta signalling in cooperation with active KRAS expression. Genes Dev. 20, 3147-3160 (2006).

9. Kojima, K. et al. Inactivation of SMAD4 accelerates KRAS ${ }^{\mathrm{G} 12 \mathrm{D}}$-mediated pancreatic neoplasia. Cancer Res. 67, 8121-8130 (2007).

10. Hill, R. et al. PTEN loss accelerates K-RAS ${ }^{G 12 D}$-induced pancreatic cancer development. Cancer Res. 70, 7114-7124 (2010).

11. Kennedy, A. L. et al. Activation of the PIK3CAVAKT pathway suppresses senescence induced by an activated RAS oncogene to promote tumorigenesis. Mol. Cell 42, 36-49 (2011).

12. Li, D., Xie, K., Wolff, R. \& Abbruzzese, J. L. Pancreatic cancer. Lancet 363 1049-1057 (2004)

13. Cho, Y., Gorina, S., Jeffrey, P. D. \& Pavletich, N. P. Crystal structure of a TP53 tumor suppressor-DNA complex: understanding tumorigenic mutations. Science 265, 346-355 (1994).

14. Joerger, A. C. \& Fersht, A. R. Structural biology of the tumor suppressor TP53 and cancer-associated mutants. Adv. Cancer Res. 2007, 1-23 (2007).

15. Asano, T. et al. The PI3-kinase/AKT signalling pathway is activated due to aberrant PTEN expression and targets transcription factors NF-kappaB and cMYC in pancreatic cancer cells. Oncogene 23, 8571-8580 (2004). 
16. Weissmueller, S. et al. Mutant TP53 drives pancreatic cancer metastasis through cell-autonomous PDGF receptor $\beta$ signalling. Cell 157, 382-394 (2014).

17. Subramanian, M. et al. A mutant TP53/let-7i-axis-regulated gene network drives cell migration, invasion and metastasis. Oncogene 34, 1094-1104 (2015).

18. Li, Z. et al. Cdkn2a suppresses metastasis in squamous cell carcinomas induced by the gain-of-function mutant TP53(R172H). J. Pathol. 240, 224-234 (2016).

19. Suzuki, H. I. et al. Modulation of miRNA processing by TP53. Nature 460, 529-533 (2009).

20. Garibaldi, F. et al. Mutant TP53 inhibits miRNA biogenesis by interfering with the microprocessor complex. Oncogene 35, 3760-3770 (2016).

21. Martello, G. et al. A microRNA targeting dicer for metastasis control. Cell 141, 1195-1207 (2010).

22. Han, L. et al. Downregulation of Dicer enhances tumor cell proliferation and invasion. Int. J. Oncol. 37, 299-305 (2010).

23. Muller, P. A., Trinidad, A. G., Caswell, P. T., Norman, J. C. \& Vousden, K. H. Mutant TP53 regulates Dicer through p63-dependent and -independent mechanisms to promote an invasive phenotype. J. Biol. Chem. 289, 122-132 (2014).

24. Su, X. et al. TAp63 suppresses metastasis through coordinate regulation of Dicer and miRNAs. Nature 467, 986-990 (2010).

25. Stindt, M. H. et al. Functional interplay between MDM2, p63/p73 and mutant TP53. Oncogene 34, 4300-4310 (2015).

26. Dong, P. et al. Mutant TP53 gain-of-function induces epithelial-mesenchymal transition through modulation of the miR-130b-ZEB1 axis. Oncogene $\mathbf{3 2}$ 3286-3295 (2013).

27. Wilczynska, A. \& Bushel, M. The complexity of miRNA-mediated repression. Cell Death Differ. 22, 22-33 (2015).

28. Jamieson et al. MiRNA molecular profiles associated with diagnosis, clinicopathologic criteria, and overall survival in patients with resectable pancreatic ductal adenocarcinoma. Clin. Cancer Res. 18, 534-545 (2012).

29. Lu, Y. et al. MiR-142 modulates human pancreatic cancer proliferation and invasion by targeting hypoxia-inducible factor 1 (HIF-1a) in the tumor microenvironments. Biol. Open 6, 252-259 (2017).

30. Zochbauer-Muller, S., Minna, J. D. \& Gazdar, A. F. Aberrant DNA methylation in lung cancer: biological and clinical implications. Oncologist 7, 451-457 (2002).

31. Kim, M. S., Lee, J. \& Sidransky, D. DNA methylation markers in colorectal cancer. Cancer Metastasis Rev. 29, 181-206 (2010).

32. Kuroki, T., Tajima, Y. \& Kanematsu, T. Role of hypermethylation on carcinogenesis in the pancreas. Surg. Today 34, 981-986 (2004).

33. Rozenblum, E. et al. Tumour-suppressive pathways in pancreatic carcinoma. Cancer Res. 57, 1731-1734 (1997).

34. Pakneshan, P., Szyf, M., Farias-Eisner, R. \& Rabbani, S. A. Reversal of the hypomethylation status of urokinase (UPA) promoter blocks breast cancer growth and metastasis. J. Biol. Chem. 279, 31735-31744 (2004).

35. Stefanska, B. et al. Definition of the landscape of promoter DNA hypomethylation in liver cancer. Cancer Res. 71, 5891-5903 (2011).

36. Shukeir, N., Pakneshan, P., Chen, G., Szyf, M. \& Rabbani, S. A. Alteration of the methylation status of tumour-promoting genes decreases prostate cancer cell invasiveness and tumorigenesis in vitro and in vivo. Cancer Res. 66, 9202-9210 (2006).

37. Juttermann, R., Li, E. \& Jaenisch, R. Toxicity of 5-aza-2'-deoxycytidine to mammalian cells is mediated primarily by covalent trapping of DNA methyltransferase rather than DNA demethylation. Proc. Natl Acad. Sci. USA 1994, 11797-11801 (1994)

38. Oka, M. et al. De novo DNA methyltransferases Dnmt3a and Dnmt3b primarily mediate the cytotoxic effect of 5-aza-2'-deoxycytidine. Oncogene $\mathbf{2 4}$ 3091-3099 (2005).

39. Chung, I. F. et al. YM500v3: a database for small RNA sequencing in human cancer research. Nucleic Acids Res. 45, 925-931 (2017).

40. Goswami, C. P. \& Nakshatri, H. PROGgeneV2: enhancements on the existing database. BMC Cancer 17, https://doi.org/10.1186/1471-2407-14-970 (2014).
41. Zhang, Y., Lui, Y. \& Xu, X. Upregulation of miR-142-3p improves drug sensitivity of acute myelogenous leukemia through reducing P-glycoprotein and repressing autophagy by targeting HMGB1. Transl. Oncol. 10, 410-418 (2017).

42. Chen, Y., Zhou, X., Qiao, J. \& Bao, A. MiR-142-3p overexpression increases chemo-sensitivity of NSCLC by inhibiting HMGB1-mediated autophagy. Cell Physiol. Biochem. 41, 1370-1382 (2017).

43. Peng, D. F. et al. Increased DNA methyltransferase 1 (DNMT1) protein expression in precancerous conditions and ductal carcinomas of the pancreas. Cancer Sci. 96, 403-408 (2005).

44. Wang, W., Gao, J., Man, X. H., Li, Z. S. \& Gong, Y. F. Significance of DNA methyltransferase-1 and histone deacetylase-1 in pancreatic cancer. Oncol. Rep. 21, 1439-1447 (2009).

45. Kishikawa, S., Murata, T., Kimura, H., Shiota, K. \& Yokoyama, K. K. Regulation of transcription of the Dnmt1 gene by Sp1 and Sp3 zinc finger proteins. Eur. J. Biochem. 269, 2961-2970 (2002).

46. Lin, R. K. et al. Dysregulation of TP53/Sp1 control leads to DNA methyltransferase-1 overexpression in lung cancer. Cancer Res. 70, 5807-5817 (2010).

47. Juttermann, R., Le, E. \& Jaenisch, R. Toxicity of 5-aza-2'-deoxycytidine to mammalian cells is mediated primarily by covalent trapping of DNA methyltransferase rather than DNA demethylation. Proc. Natl Acad. Sci. USA 91 11797-11801 (1994)

48. Wijermanns, P. et al. Low-dose 5-aza-2'-deoxycytidine, a DNA hypomethylating agent, for the treatment of high-risk myelodysplastic syndrome: a multicenter phase II study in elderly patients. J. Clin. Oncol. 18, 956-962 (2000).

49. Issa, J. J. et al. Phase 1 study of low-dose prolonged exposure schedules of the hypomethylating agent 5-aza-2'-deoxycytidine (decitabine) in hematopoietic malignancies. Blood 103, 1635-1640 (2004).

50. Kantarjian, $\mathrm{H}$. et al. Decitabine improves patient outcomes in myelodysplastic syndromes: results of a phase III randomized study. Cancer 106, 1794-1803 (2006).

51. Lubbert, M. et al. Low-dose decitabine versus best supportive care in elderly patients with intermediate- or high-risk myelodysplastic syndrome (MDS) ineligible for intensive chemotherapy: final results of the randomized phase III study of the European Organisation for Research and Treatment of Cancer Leukemia Group and the German MDS Study Group. J. Clin. Oncol. 29, 1987-1996 (2011).

52. Kantarjian, H. M. et al. Survival advantage with decitabine versus intensive chemotherapy in patients with higher risk myelodysplastic syndrome: comparison with historical experience. Cancer 109, 1133-1137 (2007)

53. Sato, N., Maehara, N., Su, G. H. \& Goggins, M. Effects of 5-Aza-2'-deoxycytidine on matrix metalloproteinase expression and pancreatic cancer cell invasiveness. J. Natl Cancer Inst. 95, 327-330 (2002).

54. Chik, F. \& Szyf, M. Effects of specific DNMT gene depletion on cancer cell transformation and breast cancer cell invasion; toward selective DNMT inhibitors. Carcinogenesis 32, 224-232 (2011).

55. Gros, $C$. et al. DNA methylation inhibitors in cancer: recent and future approaches. Biochimie 94, 2280-2296 (2012).

56. Mackenzie, T. N. et al. Triptolide induces the expression of miR-142-3p: a negative regulator of heat shock protein 70 and pancreatic cancer cell proliferation. Mol. Cancer Ther. 12, 1266-1275 (2013).

57. $W u, Y$. et al. Triptolide down-regulates TP53 gene methylation and inhibits proliferation of hepatocarcinoma SMMC-7721 cells. Chin. J. Cancer Biother. 3, 10 (2011).

58. Morran, D. C. et al. Targeting mTOR dependency in pancreatic cancer. Gut 63 1481-1489 (2014).

59. Stucky, B. J. SeqTrace: a graphical tool for rapidly processing DNA sequencing chromatograms. J. Biomol. Tech. 23, 90-93 (2012).

60. Hall, T. A. BioEdit: a user-friendly biological sequence alignment editor and analysis program for Windows 95/98/NT. Nucleic Acids Symp. 41, 95-98 (1999).

61. Bock, C. et al. BiQ analyzer: visualization and quality control for DNA methylation data from bisulfite sequencing. Bioinformatics 21, 4067-4068 (2005). 